\title{
STRATEGI KONSEP DESAIN KEMASAN KOPI SPECIALTY UNTUK INDUSTRI SKALA MIKRO
}

\author{
Zulkarnain* \\ Politeknik Negeri Jakarta \\ *Correspondin author: Zulkarnain, zulkarnain@grafika.pnj.ac.id, Depok, Indonesia
}

\begin{abstract}
Abstrak. Banyak persoalan yang muncul bagi usaha mikro ketika ingin menggunakan kemasan untuk produknya. Salah-satu persoalan bagi usaha mikro kopi specialty adalah menentukan kemasan yang tepat. Tujuan kajian ini untuk menentukan konsep struktur dan label kemasan kopi specialty yang tepat untuk industri skala mikro. Adapun metode yang digunakan adalah deskriptif kualitatif. Kajian dilakukan melalui studi literatur berupa sintesis dan analisis informasi. Dalam kajian ini mengulas mulai dari atribut produk kopi, struktur kemasan, sampai pada konsep desain kemasan dan label. Strategi jenis struktur kemasan yang paling tepat untuk industri skala mikro adalah jenis kemasan pouch, sementara strategi desain kemasan dan label adalah menggunakan warna gelap, memuat informasi produk kopi, memiliki merek, dan mempunyai tone and manner.
\end{abstract}

\begin{abstract}
Many problems arise for micro businesses when they want to use packaging for their products. One of the problems for specialty coffee micro-businesses was determining the appropriate packaging. The purpose of this study was to determine the concept of structure and label of specialty specialty coffee packaging for the micro scale industry. The method used was descriptive qualitative. The study was conducted through a literature study in the form of synthesis and analysis of information. In this study review starts from the attributes of coffee products, packaging structure, to the concept of packaging and label design. The most appropriate type of packaging structure strategy for the micro-scale industry was the type of pouch packaging, while the packaging and label design strategy was to use dark colors, load coffee product information, have a brand, and have a tone and manner.
\end{abstract}

Keywords: literature study, packaging design, specialty coffee

\section{Pendahuluan}

Kemasan dapat menjadi salah satu kendala bagi perkembangan dan kemajuan usaha mikro. Banyak persoalan yang muncul bagi usaha mikro dan calon pelaku usaha ketika ingin menggunakan kemasan yang tepat untuk produknya. Persoalan tersebut berupa struktur kemasan dan label kemasan. Struktur kemasan biasanya terkait dengan bahan dan bentuk kemasan sedangkan label kemasan biasanya terkait dengan apa yang ingin dikomunikasikan kepada konsumen.

Kebanyakan pelaku usaha mikro memiliki kekurangan keterampilan dan pengetahuan terkait teknologi dan desain kemasan sehingga menghadapi masalah dalam menentukan strategi desain kemasan yang tepat dan sesuai dengan produknya (Auttarapong 2012). Sementara, pertumbuhan nilai kemasan yang ekologis dan bergengsi dalam desain semakin meningkat (Rusko et al. 2011). Hal ini menjadi penyebab industri skala mikro kurang bisa bersaing dengan industri kopi kelas besar. Pelaku usaha mikro sudah seharusnya memahami 
bahwa kemasan yang tepat dan menarik tidak harus dengan biaya yang tinggi. Struktur kemasan yang ditempel dengan label, jika dirancang dengan baik tentu akan menjadi kemasan yang memiliki daya tarik.

Daya tarik yang dimaksud berupa daya tarik struktur maupun daya tarik label. Daya tarik struktur mengarah pada pertimbangan ergonomi dan pertimbangan perlindungan. Contoh pertimbangan ergonomi adalah mudah dibawa atau dipegang, mudah dibuka dan ditutup kembali, mudah dipajang dan disimpan, sedangkan pertimbangan perlindungan (barrier protection), yaitu menjadi pelindung produk terhadap udara, sinar matahari, jatuh, tumpukan, kuman, dan serangga yang dapat menjadi penyebab timbulnya kerusakan produk. Pertimbangan-pertimbangan tersebut akan mempengaruhi bentuk dan bahan dari kemasan itu sendiri. Sementara itu, daya tarik label mengarah pada pertimbangan estetika yang mencakup, penggunaan warna, citra, tipografi, dan tata letak. Bila pertimbangan tersebut dikombinasikan secara optimal tentu akan mempengaruhi emosi dan psikologis (respons positif) konsumen.

Produk kopi jika dilihat dari kelasnya secara luas dapat dibedakan menjadi dua, yaitu kelas specialty dan kelas komersial. Kelas specialty memiliki harga yang tinggi (premium) sedangkan kelas komersial memiliki harga yang rendah (murah). Untuk mencapai kelas specialty membutuhkan dedikasi yang tinggi, mulai dari proses penanaman, proses perawatan, proses pemanenan, proses penyangraian, sampai pengemasan. Semua proses tersebut dilakukan melalui tangan-tangan terampil yang peduli terhadap kualitas kopi.

Jika dilihat dari speciesnya secara umum kopi dapat dibedakan menjadi dua, yaitu arabika dan robusta. Arabika merupakan species yang cenderung menjadi kopi kelas specialty karena biji kopi arabika memiliki kualitas rasa dan aroma yang sangat baik, sedangkan robusta cenderung menjadi kopi komersial. Potensi pengembangan kopi specialty untuk Indonesia masih sangat terbuka karena bergesernya pangsa pasar konsumen kopi komersial ke kopi specialty (Sudjarmoko 2013). Kopi specialty memiliki nilai ekonomi yang sangat tinggi, namun jenis kopi ini tidak diproduksi secara pabrikasi karena merupakan ranahnya usaha mikro. Kajian ini membahas kemasan untuk produk kopi specialty yang ditujukan untuk membantu perkembangan usaha mikro. Adapun tujuan kajian ini adalah untuk menentukan konsep struktur dan label kemasan kopi specialty yang tepat untuk industry skala mikro.

\section{Metode}

Kajian dilakukan melalui studi literatur jenis integrative review, yaitu jenis kajian yang menyajikan dan meringkaskan keadaan semasa pengetahuan tentang topik tertentu, serta memberi kilasan tentang dukungan dan kritikan terhadap topik tersebut (Marzali 2016). Studi literatur ini mensintesis dan menganalisis informasi dengan memusatkan perhatian pada temuan-temuan seputar struktur dan desain kemasan kopi. Adapun metode penulisan yang digunakan adalah deskriptif kualitatif. Literatur diurai secara eksplisit dari berbagai penulis dan peneliti, baik mengenai pengetahuan maupun hasil penelitian. Penulisan disusun secara sistematis agar mudah dipahami, mulai dari atribut produk kopi, struktur kemasan, sampai pada konsep desain kemasan dan label.

Atribut produk kopi merupakan sifat yang menjadi ciri khas suatu kemasan. Sementara struktur kemasan yang dikaji merupakan bentuk, ukuran, dan bahan kemasan yang telah standard untuk produk kopi pada pemasok kemasan sehingga tidak perlu diuji kemampuan dalam melindungi produk (kopi). Terakhir, konsep desain kemasan dan label merupakan konsep yang dilekatkan pada kemasan yang ditujukan agar tercapainya komunikasi antara produsen dan konsumen. Adapaun bagan kerangka berpikir dapat dilihat pada Gambar 1. 


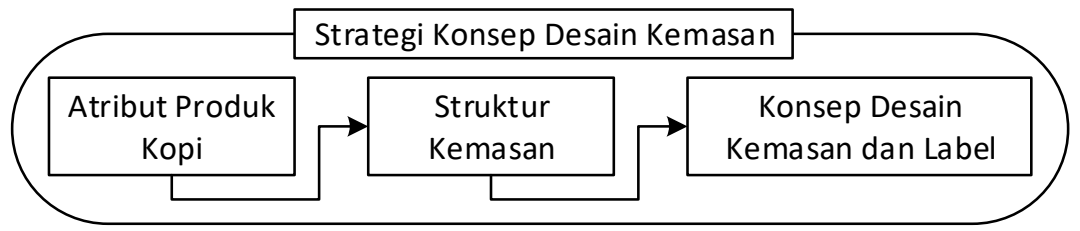

Gambar 1 Kerangka berpikir

\section{Hasil dan Pembahasan}

Bagian ini membahas mengenai atribut produk kopi, struktur kemasan kopi yang ada di pasaran, dan konsep desain kemasan kopi dan label yang direkomendasikan.

\section{Atribut Produk Kopi}

Kopi merupakan salah satu komoditas penting di dalam perdagangan dunia yang melibatkan beberapa negara produsen dan banyak negara konsumen. Kata "kopi (coffee)" berasal dari "Kaffa" yaitu nama tempat pertama kali ditemukan di wilayah Ethiopia (Mekuria, Neuhoff, and Köpke 2004). Tanaman kopi termasuk dalam famili Rubiaceae dan genus Coffea. Spesies kopi dunia terdiri dari 66\% jenis kopi arabika dan 34\% kopi robusta (Mekuria, Neuhoff, and Köpke 2004; Robertson 2006). Popularitas dan daya tarik kopi di seluruh dunia berasal dari cita rasanya yang unik, sehingga menjadi salah-satu minuman yang paling diinginkan dan sering dikonsumsi. Lebih lanjut, Hečimović et al. (2011) menyatakan bahwa kopi memiliki kepentingan sejarah, budaya, sosial dan ekonomi yang kuat.

Utami (2009) melakukan penelitian mengenai pemasaran kopi bubuk '555' di Propinsi Nusa Tenggara Barat untuk mengetahui segmentasi konsumen kopi bubuk, variabel yang mempengaruhi perilaku konsumen, serta mengetahui prospek pemasarannya. Berdasarkan penelitian tersebut diketahui bahwa terdapat 3 segmentasi yaitu: strata pendapatan rendah, strata pendapatan sedang, strata pendapatan tinggi. Variabel kebiasaan, pendidikan, harga, pendapatan, promosi dan pekerjaan berpengaruh signifikan terhadap keputusan pembelian kopi bubuk, sedangkan variabel kualitas, umur dan suku tidak berpengaruh secara signifikan. Variabel pendapatan merupakan yang paling berpengaruh terhadap keputusan membeli.

Persaingan antar sesama produsen kopi dalam era globalisasi, tidak hanya terbatas pada kemampuan masing-masing perusahaan menyajikan produk yang bermutu tinggi tetapi juga harus sesuai dengan permintaan konsumen (Utami 2009). Satyajaya et al. (2014) menyatakan tingkat kepentingan teratas dari atribut produk kopi instan dalam sachet adalah atribut rasa, aroma dan kesegaran kopi. Sementara itu Gadung, Zakaria, and Murniati (2015) menyatakan bahwa ada lima atribut produk kopi bubuk Sinar Baru Cap Bola Dunia (SB-CBD) yang memiliki kepuasan tertinggi, yaitu label halal, rasa, tanggal kadaluarsa, aroma yang khas, dan harga. Sebagaimana diketahui bahwa atribut rasa, aroma, kesegaran kopi, tanggal kadaluarsa (umur simpan) merupakan atribut yang perlu didukung oleh struktur kemasan yang baik. Sementara label halal merupakan bagian dari grafis label kemasan.

\section{Struktur Kemasan Kopi}

Kemasan kopi memiliki peran yang sangat penting dalam melindungi produk kopi. Hal yang harus dipertimbangkan pada kemasan produk kopi adalah masuknya uap air, permeabilitas O2, jalan keluarnya komponen volatile (CO2) (Robertson 2006). Berikut beberapa hal mendasar yang harus dimiliki struktur kemasan kopi:

1. Kemasan harus kedap udara dan mencegah udara masuk.

Bahan yang tepat adalah plastik dan aluminium foil karena bahan tersebut memiliki permeabilitas yang sangat kecil sehingga daya serap terhadap uap air dan gas juga kecil 
(lanah 2012). Hal ini penting karena kopi merupakan produk olahan yang bersifat higroskopis, yaitu produk yang dapat menyerap air di udara atau sebaliknya melepaskan sebagian air yang dikandungnya ke udara.

2. Kemasan harus mampu mengeluarkan gas $\mathrm{CO} 2$ dari dalam kemasan.

Berdasarkan sifat kimiawi kopi sangrai dapat menghasilkan gas $\mathrm{CO} 2$, sehingga diperlukan material ataupun desain kemasan yang mampu mengeluarkan kadar $\mathrm{CO} 2$ namun dapat menjaga kadar $\mathrm{O} 2$ dalam kemasan (Kiyoi 2010). Maka itu diperlukan kemasan yang memiliki katup (valve) karena dapat melepaskan karbon namun dapat menahan masuknya oksigen. Oksigen (O2) merupakan penentu utama dari umur simpan dan ada tiga cara utama menurunkan konsentrasi dalam kemasan, yaitu dengan: 1) menerapkan vakum tinggi segera setelah mengisi ke dalam kemasan dan kemudian penyegelan; 2) menyiram kopi bubuk dan kemasan dengan gas inert segera sebelum penyegelan; dan 3) menempatkan sachet penyerap 02 dalam kemasan (Robertson 2006).

3. Kemasan harus mampu menahan sinar ultraviolet dan kelembaban sehingga dapat mencegah oksidasi. Dalam hal ini bahan yang tepat adalah aluminium foil tetapi dalam aplikasinya aluminium foil harus dikombinasikan dengan kemasan lain (lanah 2012).

Usaha mikro umumnya tidak mendesain (struktur) kemasannya sendiri (kecuali label), tetapi menggunakan kemasan yang sudah tersedia di pasaran. Berikut ini beberapa kemasan kopi yang tersedia di pasaran:

1. Kemasan karung goni

Karung goni merupakan kemasan yang ramah lingkungan sehingga turut berperan mengurangi pemanasan global. Jenis kemasan ini banyak diaplikasikan untuk mengemas biji kopi, namun untuk kebutuhan industri (tidak untuk konsumen).

2. Kemasan kantung kertas greaseproof

Greaseproof merupakan kemasan dengan jenis kertas food grade. Ciri-ciri kemasan ini: dapat menyerap minyak kopi sehingga dapat menjaga kualitas kopi; tidak disegel (hanya digulung pada bagian penutupnya) karena digunakan hanya untuk sementara sehingga konsumen harus memindahkan kopi ke toples khusus (canister). Penggunaan jenis kemasan ini hanya untuk beberapa hari.

3. Kemasan vakum

Jenis kemasan ini membuat kedap udara di dalam kemasan sehingga dapat menjaga kualitas aroma dan rasa kopi. Namun kemasan ini tidak tepat untuk produk kopi bubuk karena mesin vakum dapat menghirup kopi bubuk juga.

4. Kemasan kaleng

Jika menggunakan bahan kaleng maka harus dipastikan tidak ada karat, karena jika terdapat karat maka kopi dapat memiliki rasa logam.

5. Kemasan plastik (transparan) atau kertas

Jika menggunakan bahan plastik atau kertas maka dapat memberi kesan bahwa produk memiliki kualitas rendah.

6. Sachet

Jenis kemasan ini memiliki ukuran yang kecil karena merupakan jenis kemasan yang langsung dibuang (disposable) setelah satu kali sajian kopi.

7. Pouch

Pouch atau disebut juga soft pack (Robertson 2006) adalah kemasan fleksibel (flexible packaging) berbentuk kantong yang dapat berdiri tegak (stand up packaging) tanpa penyangga. Kemasan jenis pouch dibuat dari laminasi aluminium foil dan polimer (Murniyati 2009). Bahan aluminum foil berfungsi untuk menahan paparan sinar matahari dan oksigen dari luar kemasan sehingga sangat tepat dalam menjaga aroma dan cita rasa kopi. Berikut tiga tipe kemasan jenis pouch (Gambar 1) yang ada di pasaran, yaitu: 
a. Stand up pouch

Tipe pouch ini merupakan kemasan yang memiliki desain yang alasnya oval, sisi kiri dan kanannya pipih. Selain itu, tipe ini adalah dapat dilengkapi fitur zipper dan valve.

b. Side gusset pouch

Tipe pouch ini memiliki desain yang menyerupai bantalan. Ciri-ciri tipe ini adalah dapat dilengkapi dengan klip dan valve.

c. Flat bottom pouch

Tipe pouch ini merupakan gabungan dari stand up pouch dan side gusset pouch. Ciri tipe ini adalah memiliki lipatan di kedua sisi-nya, datar pada bagian alasnya, dan dapat dilengkapi dengan fitur zipper dan valve.

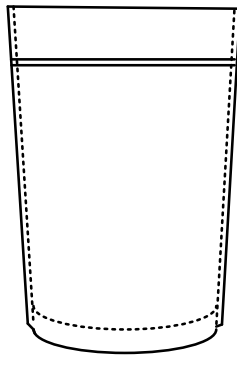

Stand up pouch

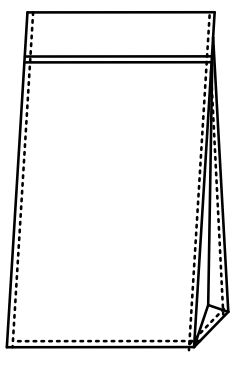

Flat bottom pouch

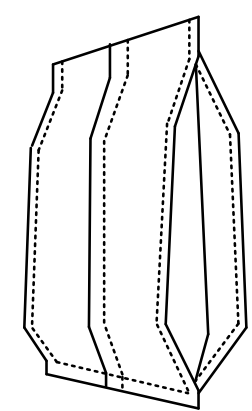

Side gusset pouch

Gambar 2 Tipe-tipe kemasan pouch

Di antara kemasan-kemasan kopi, kemasan yang memiliki perlindungan terbaik adalah kemasan kaleng dan pouch. Jenis kemasan kaleng memiliki kelebihan, di antaranya adalah tidak ada pertukaran material sehingga tidak akan terbentuk gas yang dapat mempengaruhi rasa dan aroma kopi, masa simpan bisa mencapai lebih dari 5 tahun. Namun jenis kemasan pouch memiliki keunggulan dibandingkan kemasan kaleng, yaitu dapat disematkan fitur valve. Hal ini karena karena kemasan kaleng tidak bisa ditekan (bagian bawahnya) untuk memberikan tekanan agar valve terbuka mengeluarkan gas yang ada di dalam kemasan, sedangkan pouch lebih mudah tertekan, yang berarti bahwa cukup dengan tekanan ringan dapat menghasilkan tekanan yang dapat membuka valve untuk mengeluarkan gas dan aroma kopi. Selain itu, teknologi valve yang berbahan plastik tidak mudah diaplikasikan ke dalam kemasan kaleng. Saat ini terdapat juga jenis kemasan komposit, namun yang menjadi pertimbangan tidak digunakannya jenis kemasan komposit adalah: biaya yang relative mahal, butuh ruang penyimpanan yang tidak kecil, dan teknologi saat ini belum mendukung untuk penggunaan valve.

Fitur valve (katup) pada pouch dapat membuka dan melepaskan $\mathrm{CO} 2$ ketika tekanan internal tertentu terlampaui. Setelah tekanan internal berkurang ke tingkat yang ditetapkan, katup akan menutup. Ada tiga jenis konstruksi katup yang tersedia: katup dengan topi sepenuhnya menonjol, katup dengan tutup setengah menonjol dan katup dengan tutup sepenuhnya tenggelam ke plat dasar (Robertson 2006). Pentingnya fitur valve adalah untuk:

1. Mengeluarkan gas yang ada di dalam kemasan.

Fitur valve (katup udara) dapat mengeluarkan gas pada kopi yang tertahan di dalam kemasan, namun udara dari luar kemasan tidak mudah masuk ke dalam kemasan (sifatnya satu arah) sehingga kualitas aroma dan rasa kopi selalu terjaga.

2. Memudahkan dalam menikmati aroma kopi dalam kemasan.

Fitur valve berguna sebagai sarana dalam menikmati aroma kopi meskipun kopi masih dalam keadaan disegel.

3. Mengidentifikasi kualitas (rasa dan aroma) kopi. 
Hal ini penting bagi konsumen untuk mengenali, mengukur dan membandingkan tingkat kualitas aroma kopi.

Jenis kemasan pouch juga dapat disematkan fitur zipper yang berfungsi untuk memudahkan konsumen dalam hal membuka dan menutup kemasan sehingga kualitas kopi dapat terjaga. Konsumen tidak perlu menuangkan atau memindahkan kopi yang terdapat dalam kemasan ke wadah lain. Selain itu, fitur zipper juga dapat memudahkan pelaku usaha karena praktis dalam proses pengemasan.

Strategi jenis kemasan yang paling tepat untuk industri skala mikro adalah jenis kemasan pouch, hal ini karena: hemat ruang penyimpanan daripada kemasan botol atau kaleng; selama proses transportasi lebih ringan dalam penggunaan kendaraan angkutan dan hemat bahan bakar; mudah ditata rapi di rak pajang; dapat disegel dengan menggunakan mesin sealer yang sederhana; dan bisa disematkan fitur zipper.

\section{Konsep Desain Kemasan dan Label}

Siswanto, Damayanti, and Dewi (2011) melakukan penelitian redesain kemasan produk kopi instan dengan bentuk (struktur) cup yang hasilnya berupa 10 kriteria kebutuhan kemasan cup kopi instan pada produk Torabika Sejodoh, seperti kemasan cup kopi instan yang tebal dan kuat, mencantumkan informasi yang lengkap, menarik, terbuat dari bahan yang aman untuk kesehatan, nyaman digunakan, praktis, mudah dibuka dan dikonsumsi, berukuran besar, mempunyai label yang terbaca jelas dan terpasang dengan baik, dan yang terakhir mudah dibawa. Hasil redesain kemasannya ditunjukkan pada Gambar 2. Terdapat beberapa kelemahan dalam proses desainnya, seperti (1) responden hanya pada orang yang tinggal di Bandung; (2) ketidakjelasan antara elemen desain dan atribut kemasan; (3) referensi kemasan untuk penelitian hanya ada satu; dan (4) tidak mencakup biaya kemasan.

Corso and Benassi (2015) juga melakukan penelitian kemasan kopi instan tetapi dengan bentuk (struktur) glass. Hasil redesain kemasannya ditunjukkan pada Gambar 3. Lebih lanjut disebutkan bahwa desain memiliki dampak penting pada minat beli konsumen. Peningkatan minat pembelian dipengaruhi oleh kemasan yang lebih modern dan label yang lebih coklat yang menunjukkan kopi panggang. Konsumen lebih suka mengasosiasikan produk dengan gambar secangkir kopi panas kecil. Selain itu, konsumen juga lebih menyukai citra biji kopi hijau dan roasted coffee bean di sebelah secangkir kopi dan menyukai informasi terkait diferensiasi produk (asal, jenis, jumlah dan fungsi antioksidan) yang disajikan dalam bentuk bagan penjelasan di bagian belakang kemasan kopi. Penelitian tersebut telah menghasilkan atribut kemasan (glass shape, glass lid color and label, information and brand) dan elemen desain (gambar cangkir kopi, roasted coffee bean, biji kopi hijau). Namun, tidak ada tone and manner yang menggambarkan suasana atau karakter kemasan dan label. Padahal, penting bagi setiap produsen untuk merancang kemasan produk kopi yang memiliki sense of belonging terhadap sasaran konsumen (Harith, Ting, and Zakaria 2014). 


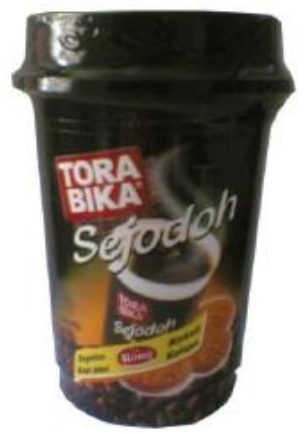

Kondisi saat ini

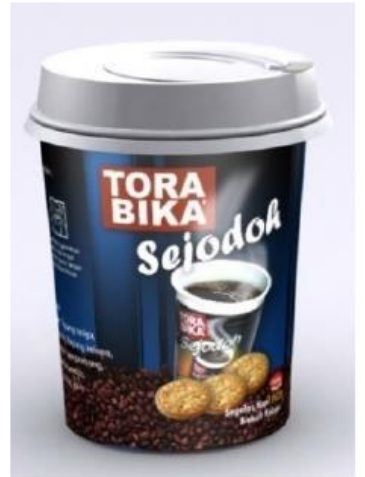

(1)

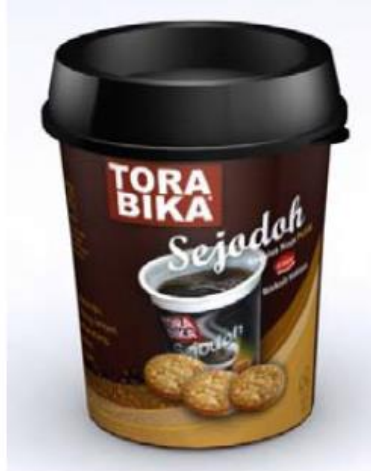

(2)

Hasil redesain kemasan (1) dan (2)

Gambar 3 Kemasan kopi instan dengan bentuk cup

Sumber: Siswanto, Damayanti, and Dewi (2011)

Disisi lain, Harith, Ting, and Zakaria (2014) menyatakan bahwa konsumen memperhatikan perbedaan yang dimiliki oleh setiap kemasan kopi di pasar dan membeli apa yang disukai berdasarkan persepsinya. Pandangan keseluruhan (penampilan kemasan, merek dan harga) dari kemasan kopi berkorelasi satu-sama lain untuk menyampaikan pesan sebagai pertimbangan selama proses pembelian. Lebih lanjut dinyatakan bahwa faktor yang menentukan desain kemasan kopi adalah penampilan, pesan, menarik, dan warna gelap. Sementara itu, Stanley and Elrod (2014) menjelaskan bahwa Konsumen terpaku terutama pada nama merek dan campuran kopi (coffee blend), dan hanya berfokus pada negara asal atau fitur khusus (fair trade atau organic) yang terletak di dekat titik pusat kemasan, dalam jarak dekat dengan nama merek. Pandangan konsumen jatuh di titik pusat kemasan. Dengan demikian, penting untuk memasukkan informasi yang paling berpengaruh dalam bidang kemasan.
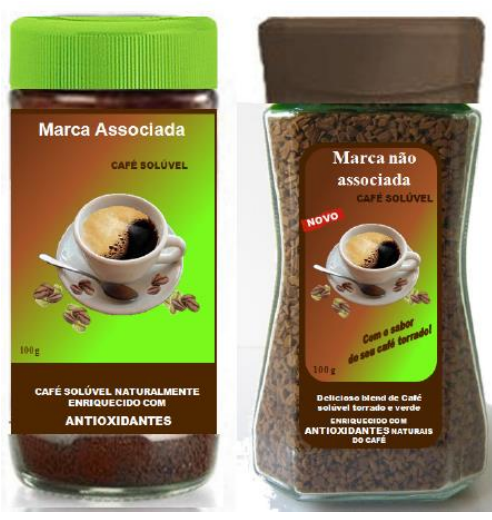

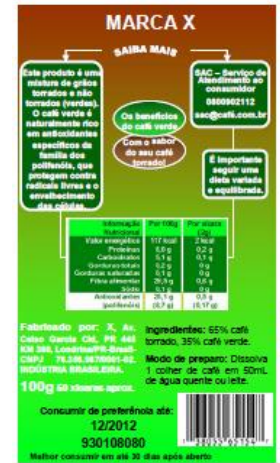

A

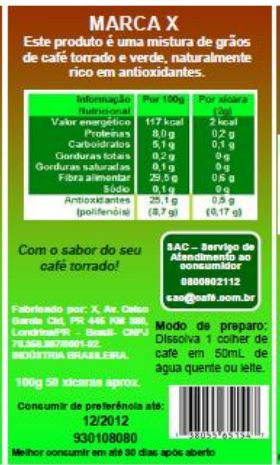

B

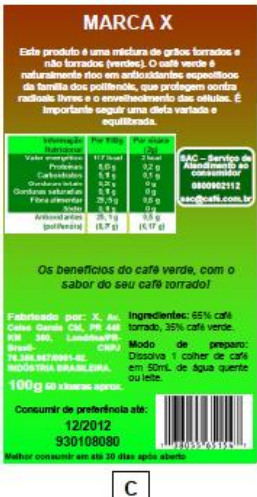

C

Gambar 4 Kemasan kopi instan dengan bentuk glass dan tiga alternatif label Sumber: Corso and Benassi (2015)

Penelitian Harith, Ting, and Zakaria (2014) mengenai persepsi konsumen terhadap kemasan kopi dan hubungan antara tampilan, merek, dan harga yang mempengaruhi sikap konsumen untuk membeli. Sementata Stanley and Elrod (2014) menyoroti bagaimana konsumen menentukan kualitas kopi dengan memahami tampilan kemasan yang dilihat ketika berbelanja. Kedua penelitian tersebut memiliki kesamaan bahwa kemasan kopi yang baik akan membentuk persepsi konsumen yang baik pula terhadap produk dan merek produk sehingga 
meningkatkan kepercayaan terhadap merek yang berujung pada keputusan membeli produk tersebut.

Penelitian Fransesca et al. (2016) telah berhasil menghasilkan tone and manner untuk kemasan kopi produk premium. Namun untuk memperoleh hasil yang akurat sesuai dengan kondisi saat ini, maka perlu penelitian yang melalui pengolahan data yang terukur untuk meningkatkan branding di tengah pasar yang semakin kompetitif. Lebih lanjut dalam penelitiannya dinyatakan bahwa kemasan dan label akan membentuk persepsi konsumen dalam meningkatkan kepercayaan terhadap merek. Kemasan dan label produk kopi yang dirancang haruslah unik, special attention, dan jujur dalam menulis informasi produk. Informasi produk kopi perlu lebih detail, misalnya lokasi geografis pertanian, metode pengolahan biji kopi, dan informasi tentang produk kopi organik.

Mohede, Tumbuan, and Tielung (2018) penelitian ini menghasilkan faktor utama dalam perancangan kemasan kopi yang terdiri dari Aesthetic of packaging, Protection and Environmental, dan Promosi Kemasan. Aesthetic of packaging memiliki makna bahwa warna kemasan harus tepat, ukuran kemasan berdasarkan pada kebutuhan konsumen, bentuk kemasan harus nyaman dan menarik. Protection and Environmental merupakan daya tahan kemasan, kemasan yang ramah lingkungan, dan semi disposable. Promosi Kemasan yang dimaksud berupa penulisan bonus pada kemasan (misal, beli satu dapat satu), dan penulisan diskon yang tercantum pada kemasan. Lebih lanjut disebutkan bahwa aesthetic of packaging merupakan faktor terpenting dalam perancangan kemasan. Aesthetic of packaging yang dimaksud terdiri dari ukuran, bentuk, dan warna. Walaupun demikian ada elemen lain juga yang seharusnya dipertimbangkan, seperti citra dan tipografi.

Berdasarkan kajian dari berbagai literatur diperoleh bahwa strategi konsep desain kemasan dan label adalah:

1. Menggunakan warna gelap.

Warna gelap yang dimaksud merupakan warna yang mengesankan gelap seperti hitam, coklat, dan lainnya.

2. Memuat informasi produk kopi.

Salah satu ciri khas kopi specialty yang berbeda dengan jenis kopi lainnya adalah memiliki banyak informasi, seperti wilayah asal, perkebunan kopi spesifik, varietas kopi, ketinggian tanam, metode pengolahan, tanggal roasting, metode roasting, karakteristik rasa, dan lainnya.

3. Memiliki merek.

Merek diperlukan sebagai identitas produsen agar mudah dikenali oleh konsumen

4. Mempunyai tone and manner

Tone and manner menggambarkan suasana atau karakter kemasan dan label yang disesuaikan dengan target pasar.

\section{Simpulan}

Strategi jenis kemasan yang paling tepat untuk industri skala mikro adalah jenis kemasan pouch, hal ini karena: hemat ruang penyimpanan daripada kemasan botol atau kaleng; selama proses transportasi lebih ringan dalam penggunaan kendaraan angkutan dan hemat bahan bakar; mudah ditata rapi di rak pajang; dapat disegel dengan menggunakan mesin sealer yang sederhana; dan bisa disematkan fitur zipper. Berdasarkan kajian dari berbagai literatur diperoleh bahwa strategi desain kemasan dan label adalah menggunakan warna gelap, memuat informasi produk kopi, memiliki merek, dan mempunyai tone and manner. 
Kajian ini telah berhasil merancang strategi desain kemasan kopi specialty, untuk pengembangan lebih lanjut dapat dilakukan kajian mengenai visualisasi grafis kemasan untuk produk kopi specialty.

\section{Daftar Pustaka}

Auttarapong, D. 2012. "Package Design Expert System Based on Relation between Packaging and Perception of Customer." Procedia Engineering 32: 307-314. https://doi.org/10.1016/i.proeng.2012.01.1272.

Corso, Marinês P., and Marta De T. Benassi. 2015. "Packaging Attributes of Antioxidant-Rich Instant Coffee and Their Influence on the Purchase Intent." Beverages 1 (4): 273-291. https://doi.org/10.3390/beverages1040273.

Fransesca, Baby Amelia S, Ina Primiana, Nury Effendi, and Aldrin Herwany. 2016. "Impact of Coffee Product Labeling and Packaging on Purchase Behavior with Mediating of Brand Image and Brand Trust." Academy of Strategic Management Journal 15: 49-53.

Gadung, Adiguna, Wan Abbas Zakaria, and Ktut Murniati. 2015. "Analisis kepuasan dan Loyalitas Konsumen Kopi Bubuk Sinar Baru Cap Bola Dunia (SB-CBD) di Kota Bandar Lampung." Jurnal Ilmu-llmu Agribisnis 3 (4). http://jurnal.fp.unila.ac.id/index.php/JIA/article/view/1086.

Harith, ZT, CH Ting, and NNA Zakaria. 2014. "Coffee packaging: Consumer perception on appearance, branding and pricing." International Food Research Journal 21 (3). http://www.ifrj.upm.edu.my/21\%20(03)\%202014/2\%20IFRJ\%2021\%20(03)\%202014\% 20Harith\%20345.pdf.

Hečimović, Ivana, Ana Belščak-Cvitanović, Dunja Horžić, and Draženka Komes. 2011. "Comparative study of polyphenols and caffeine in different coffee varieties affected by the degree of roasting." Food Chemistry 129 (3): 991-1000. https://doi.org/10.1016/i.foodchem.2011.05.059.

lanah, Nayiratul. 2012. "Pengaruh Bahan Kemasan Terhadap Perubahan Kadar Air Kopi Bubuk (Coffea Sp.) pada Berbagai Suhu Dan Rh Udara." Sarjana Skripsi, Universitas Jember. http://repository.unej.ac.id/handle/123456789/17438.

Kiyoi, Laura. 2010. "Determining the Optimal Material for Coffee Packaging: Oxygen Transmission Rates and Ink Abrasion Resistance." Bachelor Thesis, The Faculty of the Graphic Communication Department, California Polytechnic State University. https://digitalcommons.calpoly.edu/cgi/viewcontent.cgi?referer=https://scholar.googl e.com/\&httpsredir=1\&article=1023\&context=grcsp.

Marzali, Amri. 2016. "Menulis Kajian Literatur." Etnosia: Jurnal Etnografi Indonesia 1 (2): 27-36. https://doi.org/10.31947/etnosia.v1i2.1613.

Mekuria, Tadesse, D Neuhoff, and U Köpke. 2004. "The status of coffee production and the potential for organic conversion in Ethiopia." Conference on International Agricultural Research for Development, Berlin. 
Mohede, Christian Elroy, WJF Alfa Tumbuan, and Maria VJ Tielung. 2018. "Analysis of packaging elements and its impact to consumers buying decisions using factor analysis tool on coffee packaging products." Jurnal EMBA: Jurnal Riset Ekonomi, Manajemen, Bisnis dan Akuntansi 6

648-657. https://ejournal.unsrat.ac.id/index.php/emba/article/view/19626.

Murniyati, Murniyati. 2009. "Penggunaan retort pouch untuk produk pangan siap saji." Squalen Bulletin of Marine and Fisheries Postharvest and Biotechnology 4 (2): 55-60. https://www.bbp4b.litbang.kkp.go.id/squalenbulletin/index.php/squalen/article/view/148.

Robertson, Gordon L. 2006. Food Packaging: Principles and Practice. Second Edition ed.: CRC Press.

Rusko, Elina, Sanna Heiniö, Virpi Korhonen, Jali Heilmann, Toni-Matti Karjalainen, Panu Lahtinen, and Marja Pitkänen. 2011. Messenger package-integrating technology, design and marketing for future package communication. (Finland: VTT). https://www.vttresearch.com/sites/default/files/pdf/tiedotteet/2011/T2586.pdf.

Satyajaya, Wisnu, Azhari Rangga, Fibra Nurainy, and Harun Al Rasyid. 2014. "Proses pengambilan keputusan konsumen dan atribut produk kopi instan dalam sachet." Jurnal Teknologi \& Industri Hasil Pertanian 19 (3): 297-306. http://jurnal.fp.unila.ac.id/index.php/JTHP/article/view/613.

Siswanto, Daniel, Kristiana Asih Damayanti, and Vilia Sutra Kusuma Dewi. 2011. "Perancangan ulang kemasan cup kopi instan berdasarkan User-Centered Design." Inasea Journal 12 (1): 22-32. https://research.binus.ac.id/publication/21169421-A122-40BA-9FA0B0373F2B164A/perancangan-ulang-kemasan-cup-kopi-instan-berdasarkan-usercentered-design/.

Stanley, Sarah, and Cassandra Elrod. 2014. "Perceived Quality through Package Design : an Eye Tracking Study." Issues in Information Systems 15 (2): 375-382. https://doi.org/10.48009/2 iis 2014 375-382.

Sudjarmoko, Bedy. 2013. "Prospek pengembangan industrialisasi kopi Indonesia." Sirinov 1 (3): 99-110.

Utami, Riza Wahyu. 2009. "Segmentasi dan analisis perilaku konsumen kopi bubuk." JSEP (Journal of Social and Agricultural Economics) (2): $49-58 \% \mathrm{~V} 3$. https://jurnal.unej.ac.id/index.php/JSEP/article/view/410. 